\title{
A ANGÚSTIA MÉDICA: REFLEXÕES ACERCA DO SOFRIMENTO DE QUEM CURA
}

[The Medical Anguish: reflections about the suffering faced by who heal]

André Luiz Picolli da Silva*
Mário Aurélio Aguiar Teixeira**

RESUMO: Pretende-se demonstrar como o status social alcançado pela Medicina, acaba se transformando em um fator gerador de angustia e adoecimento para a classe médica como um todo. No cotidiano das instituições de saúde, é possível observar como os profissionais de Medicina são revestidos de um poder social que, ao mesmo tempo em que Ihes fornece grande prestigio, Ihes cobra responsabilidades extremas. A sociedade exige cada vez mais, que o médico seja capaz de solucionar de maneira rápida eficiente e certeira todos os problemas que lhe são apresentados, desconsiderando as limitações humanas desse profissional. Estranhamente, essa forma de pensar e de agir é incentivada pela própria formação acadêmica, pois esta, faz com que o estudante de Medicina, futuro médico, acredite que possua qualidades quase sobre-humanas. Porém, ao deparar-se com a realidade limitadora do cotidiano, o médico já formado, frustra-se ao perceber a impossibilidade de esgotar toda a demanda que lhe é apresentada, na forma que Ihe é exigido. Dessa maneira, acaba desenvolvendo sentimentos de angústia profunda, decorrentes dessa frustração. Como seu status social desaprova a demonstração de sinais de dificuldade ou insegurança, o médico se auto-proíbe de externalizar a angústia sentida, acabando por abafar seus sentimentos, sofrendo calado e isolado, construindo sua própria prisão, transformando-se em um ser que sofre, sem mostrar que sofre. Desse modo, este artigo objetiva ser um chamado de alerta não só para a classe médica, mas também, para todos os que trabalham na área da Saúde, no sentido de repensarmos nossas formas de atuação enquanto profissionais.

PALAVRAS-CHAVE: Medicina; Formação acadêmica; Angústia, Saúde; Médico.

\footnotetext{
* Psicólogo. Mestrando pelo programa de Pós-graduação em Psicologia da Universidade Federal de Santa Catarina.

** Médico Psiquiatra. Doutor em Psiquiatria pela Escola Paulista de Medicina Professor adjunto do Curso de Graduação em Medicina da Universidade Federal de Santa Catarina.
}

\section{INTRODUÇÃO}

Quando se estuda o fenômeno saúde é possível observar que, as diversas concepções de saúde, bem como as maneiras de seu estabelecimento e suas diversas formas de manutenção, variam histórica e culturalmente. Entretanto, freqüentemente ocorre a falsa impressão de que se chegou ao modelo ideal de promoção e manutenção de saúde, talvez por causa de um exagerado etnocentrismo aliado a um desconhecimento histórico. Essa atribuição de normalidade e naturalidade não é prejudicial apenas à sociedade que elege essa determinada forma de pensar a saúde, mas também é, principalmente, para os diversos profissionais que estão incumbidos de manter esse pensamento, sendo estes cobrados severamente quando o mesmo não ocorre dentro dos moldes esperados.

Dentro de nossa atual sociedade, nesse início do século XXI, encontra-se a figura do médico como o principal estabelecedor daquilo que é entendido por saúde, recaindo sobre esse, praticamente toda a responsabilidade sobre o "sucesso" ou "fracasso" de um tratamento. Sendo o médico, então, entendido como alguém com tamanha capacidade, não é de estranhar que muitas vezes ele seja revestido de um caráter quase mítico, como se fosse um ser mágico capaz de solucionar todos os problemas existentes.

Tal situação, que num primeiro momento poderia ser vista por alguns (e principalmente pelo próprio médico) como uma grande vantagem para cada indivíduo que pertence a esta classe profissional, revela-se na prática, uma verdadeira caixa de Pandora, a partir do momento em que o médico é chamado a ser um solucionador de todas as mazelas existentes. Esta posição privilegiada que o médico ocupa assemelha-se a um veneno misturado ao mel, sendo ao mesmo tempo doce e mortal. A sociedade vê apenas os louros colhidos pela Medicina, sem perceber a dor individual de cada médico, que sofre em solidão por vivenciar uma realidade angustiante, muitas vezes maior do que suas possibilidades humanas. 


\section{A INSTITUIÇÃO MÉDICA}

A aquisição de uma identidade profissional, em qualquer área, faz-se principalmente a partir de uma introjeção dos modelos exteriores apresentados ao indivíduo. Para que essa introjeção ocorra da melhor forma possível, os diversos ramos do saber criaram suas respectivas instituições a fim de favorecer e organizar a formação daqueles que os procuram. O modelo institucional torna-se, desse modo, uma faca de dois gumes, pois ao mesmo tempo em que fornece a educação necessária, também molda seus membros da forma a reproduzirem suas verdades estabelecidas, evitando ao máximo alterar a ordem vigente das coisas. Tal atitude pode ser entendida como a produção de uma alienação como afirma $\operatorname{LANE}$ (1986, p. 42): “A alienação se caracteriza, ontologicamente, pela atribuição de naturalidade aos fatos sociais". Desse modo, toda instituição tende a formar membros herdeiros de seus conhecimentos, mas, ao mesmo tempo, com um certo grau de alienação (por atribuir naturalidade aos seus conhecimentos) para evitar que estes mesmos membros possam utilizar seus conhecimentos adquiridos contra a própria instituição.

A alienação tem uma relação muito próxima com o poder, assim, quanto mais poderosa for uma instituição, menos os seus membros poderão questioná-la diretamente. Para que o poder permaneça existindo, um controle rígido é exercido sobre os integrantes do grupo, a fim de evitar questionamentos que poderiam levar a mudanças estruturais. $\mathrm{Na}$ instituição médica tal controle é observado já no início do curso de Medicina, quando os alunos são "forçados" a terem praticamente dedicação exclusiva ao curso, passando noites a fio decorando terminologias e conceitos, organizando seus horários para o estudo, sacrificando sua vida pessoal em detrimento da profissional, etc. O estudante de Medicina aprende logo que, para ser um bom médico, deve se autodisciplinar, a fim de poder vencer a excessiva carga de matérias que Ihes são impostas. Esta técnica, na verdade, é uma eficiente forma de produzir o futuro médico dócil, pois quanto mais tempo o estudante leva para decorar, menos tempo ele tem para questionar o sistema educacional em que está inserido. Conseqüentemente, no futuro não estará apto para questionar as atividades médicas (por falta desse treino) com as quais se defrontará no cotidiano, tendo que resignarse a reproduzi-las como seus mestres lhe ensinaram, caracterizando-se a alienação médica.

A instituição médica, assim, não trai a sua herança religiosa, exigindo de seus neófitos, antes de qualquer coisa, a disciplina e a obediência. Para FOUCAULT (1987, p. 143),
"A disciplina fabrica indivíduos, ela é a técnica específica de um poder que toma os indivíduos ao mesmo tempo como objetos e como instrumentos de seu exercício". O jovem médico, desse modo, é transformado não só em instrumento, mas também em objeto da Medicina, ou em outras palavras, em um combustível necessário para que a "máquina da saúde" continue funcionando. Essa máquina é detentora de um enorme poder social, compartilhado por seus membros, e que para ser mantido, necessita do treinamento (e sacrifício) de cada novo indivíduo que requeira parte dele.

Coube à instituição médica o poder social de atuar sobre a vida e a morte, mas para manter tal poder, ela teve que estabelecer um local e uma forma para exercê-lo.

O exame combina as técnicas da hierarquia que vigia e as da sanção que normaliza. É um controle normalizante, uma vigilância que permite qualificar, classificar e punir. Estabelece sobre os indivíduos, uma visibilidade através da qual eles são diferenciados e sancionados. É por isso que em todos os dispositivos de disciplina, o exame é altamente ritualizado. Nele vêm-se reunir a cerimônia do poder e a forma da experiência, a demonstração da força e o estabelecimento da verdade... Uma das condições essenciais para a liberação epistemológica da Medicina no fim do século XVIII foi a organização do hospital como aparelho de examinar. (FOUCAULT, 1987, p. 154).

A Medicina, assim, estabeleceu o exame como sua atividade básica, e caracterizou o hospital como seu lugar por excelência. Dessa forma, a instituição médica encontrou o "lugar" para exercer seu poder, não só para com a sociedade, mas principalmente para com seus próprios integrantes. O hospital tornou-se, desse modo, o melhor local para legitimar a autoridade médica sobre os próprios médicos.

A coerção sobre o futuro médico - que, enquanto estudante durante a faculdade, suportou a limitação de seus pensamentos e de seus sentimentos - pode chegar ao auge com a limitação de sua vontade, ou seja, com a limitação do seu próprio corpo, quando o estudante ingressa integralmente em um hospital, com o início de sua residência médica. O jovem médico que opta pela residência sabe, que terá de passar literalmente alguns anos num estado de liberdade vigiada que também poderia ser entendida como uma prisão semi-aberta, onde encontrará, entre outras coisas, horas excessivas de trabalho com uma sobrecarga de tarefas aliada à privação de descanso e sono. Isto faz com que residência médica, na verdade, esteja longe de ser um instrumento de formação, aproximando-se muito mais de um sistema final de condicionamento que garantirá uma saída 
uniforme de profissionais no mercado, para realizarem a manutenção de um "admirável mundo novo". ${ }^{1}$

Ao se estudar a residência médica, também é interessante realizar uma observação sob seu aspecto de rito de passagem. O jovem médico abandona seu lar, e sua família, e vem para sua nova "residência", para preparar-se para sua nova família, a Medicina. Em outras palavras, o estudante, que até aqui resistiu à ideologia dominante como sendo a forma convencionada da verdade, a partir desse ponto irá despir-se de tudo que seja contrário a esta ideologia, sob pena de não ser aceito na sua nova família, e tornar-se um proscrito.

É possível observar, desse modo, que a instituição médica se compara a uma grande mãe ou pai que protege seus filhos dos perigos do mundo. Porém, essa/e mesma/o mãe/pai já desgastada/o pela vida e pelos anos de sofrimento, sente um intenso ciúme da suavidade e beleza de suas filhas, e do vigor e ímpeto de seus filhos, exigindo que estes sacrifiquem suas melhores qualidades e anseios pessoais em holocausto como pagamento por sua proteção, e age, assim, para que estes não experimentem a felicidade, que ela/e, já amarga não consegue mais sentir. Um exemplo disso é a dificuldade que muitos médicos apresentam em ter um relacionamento conjugal/familiar estável, devido ao excesso de trabalho e responsabilidades profissionais. Nas palavras de GOFFMAN (1987, p. 22):

As instituições totais são também incompatíveis com outro elemento decisivo de nossa sociedade - a família. A vida familial é, às vezes, contrastada com a vida solitária, mas, na realidade, um contraste mais adequado poderia ser feito com a vida em grupo, pois aqueles que comem e dormem no trabalho, com um grupo de companheiros de serviço, dificilmente podem manter uma existência doméstica significativa... Independentemente do fato de determinada instituição total agir como força boa ou má na sociedade civil, certamente terá força, e esta depende em parte da supressão de um círculo completo de lares reais ou potenciais.

\section{A EDUCAÇÃO MÉDICA}

Todo profissional inserido no mercado de trabalho possui suas maneiras próprias de atuação que o caracterizam frente aos demais profissionais. Boa parte dessas características, são desenvolvidas na sua própria ação

Admirável mundo novo - escrito em 1932 por Aldous Huxley, descreve um prognóstico pessimista em relação à humanidade, onde seus membros seriam condicionados desde antes de seus nascimentos visando a manutenção de uma ordem social pré-estabelecida. cotidiana, porém, ninguém questiona o fato de que a formação do profissional deixa marcas profundas que se manifestarão em maior ou em menor grau ao longo de sua vida. Para BOULOS (1998), o ensino médico no Brasil - que desde de seu inicio foi marcado pelo modelo francês/ napoleônico de priorizar a formação de profissionais para o mercado - fez com que as universidades buscassem a contratação de professores/médicos que sabiam fazer, o que não necessariamente significava saber ensinar. Desse modo, a formação médica acabou por ter uma preocupação maior para com a atuação prática e menor para com as pesquisas, contribuindo para que o médico permanecesse com a visão bio-fisiológica de doença, dentro dos moldes cartesianos biomédicos, tendo dificuldade de compreender um organismo histórico-bio-psico-social que adoece.

A atuação do profissional de Medicina, seu modo de agir e de pensar, estão intimamente relacionado com a sua formação acadêmica (como qualquer profissional), entretanto, como a Medicina possui grande influência dentro da sociedade, isso faz com que ela mesma sofra fortes pressões de outros setores interessados em lucrar com essa influência. Infelizmente, tais pressões acabam repercutindo principalmente sobre o estudante que, por ainda não possuir uma sólida forma de investigação e questionamento (visto que ainda está em formação), acaba sendo fortemente marcado por tudo aquilo que lhe é apresentado como "verdade". Assim, na atividade do ensino médico, muitas vezes, é possível encontrar uma distorção de valores em relação ao que seja saúde ou práticas médicas, o que acaba por distorcer a própria atuação da Medicina. Como afirma PESSINI (1994, p.125):

A estratégia dos trustes farmacêuticos é de convencer que a saúde é uma mercadoria como outra qualquer... A compra de medicamentos (e dos atos médicos) é o único meio de preservar, melhorar e restabelecer a saúde. Tenta-se convencer a classe médica e ao público em geral, que um dia todas as doenças serão curadas pela ação de um procedimento farmacológico e/ou cirúrgico. $\mathrm{O}$ alvo é sempre o biológico, não levando em conta os problemas psíquicos, sociais ou ambientais da pessoa. Chega-se ao extremo da medicação de um problema social, como denunciou Ivan Illich.

Além da visão orgânico-determinista sobre a saúde/ doença, o jovem estudante é "obrigado" a internalizar conceitos como doença/mal, saúde/bem. Isto, no futuro, poderá vir a ser um fator gerador de angústia, pois quando o jovem médico se deparar com um problema que não seja orgânico, ou que não seja passível de uma intervenção medicamentosa/cirúrgica (na qual praticamente ficará impossibilitado de "eliminar" a patologia), tenderá a desenvolver a fantasia de: saúde = médico bom $/$ doença $=$ médico mal. 
A fragilização do estudante, que acarretará no posterior surgimento desse tipo de pensamento, também ocorre devido ao pouco contato humano que o estudante de Medicina realiza durante sua formação, o que levará ao surgimento de inseguranças quando este se deparar com uma pessoa real que sofre. Para defender-se dessas inseguranças (completamente normal perante o desconhecido), o estudante de Medicina é "treinado" a desenvolver duas características tidas pela sociedade como marcantes na Medicina atual, ou seja, a "despersonalização do paciente", e a "onipotência".

A despersonalização do paciente é um recurso muito útil, sobretudo, para baixar a ansiedade de ter que submeter uma pessoa a algum tipo de tratamento demasiado traumático. Os estudantes aprendem essa técnica, por intermédio da idéia de que é necessário um afastamento emocional do paciente, afim de não prejudicar a objetividade cientifica da atividade. O médico, em tal situação, "nega" que está lidando com uma pessoa e "vê" apenas uma patologia, ou um órgão doente; assim, alivia seus próprios sentimentos de culpa por infligir a alguém algo doloroso, pois inconscientemente, segundo essa ótica, não está agindo sobre uma pessoa e sim sobre uma doença. Tal mecanismo é relativamente válido, principalmente na Medicina, a fim de manter a saúde e sanidade do médico. Entretanto, o problema existe quando ele é utilizado de forma indiscriminada, e estereotipada.

Ao estudante de Medicina, desde o início, é oferecida uma relação sem resposta humana. Até o terceiro ano, ele está só diante da peça de anatomia, da lâmina ao microscópio, do tubo de ensaio, do inseto, do rato, da rã e da cobaia. Quando se vê com o doente, já transcorrido um terço do curso, tende a estabelecer e introjetar, o mesmo modelo relacional que obteve com o objeto de observação ou experiência. (PERAZZO, 1990, p. 139).

Em relação à questão da onipotência, esta é outra característica que pode ser considerada um fruto da formação. MELLO FILHO (1992), afirma ser necessário uma dose de onipotência para que o médico consiga exercer sua prática profissional. Este fato é plausível, porém, o problema novamente reside sobre os extremos. Com o excesso de onipotência, o médico acaba por isolar-se do restante da equipe e até mesmo do próprio paciente, correndo o risco de alimentar fantasias megalomaníacas e, conseqüentemente, desenvolver patologias a partir das frustrações ocasionadas quando do confronto com a realidade que friamente lhe demonstra que não pode tudo, como crê. A onipotência, desse modo, apesar de necessária pode ser perigosa, quando, acaba gerando um afastamento do médico das demais pessoas. Para ZAIDHAFT (1990), a onipotência nos médicos é desenvolvida quando estes começam a acreditar na fantasia de dominarem a vida e a morte. Essa fantasia de poder sobre a morte, surge logo no início do curso de formação, quando os estudantes que buscavam aprender a curar, deparam-se antes de tudo com cadáveres. Assim, para defenderem-se dessa frustração, precisam acreditar que são superiores a esta situação (da morte) e que isso não Ihes incomoda, acabando por reproduzir mais tarde esse modo de agir com seus pacientes vivos.

Nesse encontro com o cadáver, inicia-se nos alunos o processo de desenvolvimento de mecanismos de defesa indispensáveis para a futura profissão. Se, inicialmente esse contato é difícil, por outro lado, o cadáver torna-se objeto de satisfações libidinais dos alunos. Por seu desamparo e passividade, o cadáver permite aos alunos experimentar uma sensação de poder absoluto. A relação mantida com o cadáver é conservada inconscientemente e se torna a relação ideal, que será buscada, alguns anos depois, no encontro com os pacientes. (ZAIDHAFT, 1990 p. 127).

O futuro médico, dessa maneira, pode ser prejudicado pela sua própria formação, como também alerta ILLICH (1984).

Assim sendo, tomando-se como correto o conceito de ZIMERMAN (1992), de que a formação de um "bom médico" deve pautar-se sobre o tripé: conhecimentos mais habilidades mais atitudes, observa-se que com exceção das habilidades, há falhas consideráveis nos outros dois elementos que constituem o tripé de formação. Isto faz com que os alunos de Medicina acabem por formar-se com visões estereotipadas do que seja a saúde e as formas de intervenção médica, reproduzindo, em algum momento, estas visões de maneira negativa na sociedade, perpetuando um sistema perverso que prejudica tanto ou mais do que ajuda.

\section{A REALIDADE MÉDICA}

Nietzsche sustentava a idéia de que quanto menos uma pessoa sabe mandar sobre sua própria vida, mais avidamente deseja alguém que mande por ela, quer esse alguém seja, uma classe política, um Deus, um dogma, um médico, etc, e atribuía tal desejo a uma fraqueza da vontade. Desse modo, é possível considerar que os indivíduos da sociedade, com sua vontade fraca, não querendo o trabalho de serem responsáveis por suas próprias vidas, abrem mão de seus poderes individuais de controle, em detrimento desse "alguém" que mande.

A Medicina (como outras instituições) aceitou esse poder em troca do trabalho de ter a responsabilidade sobre a existência dos indivíduos. Isso, foi um grande passo para a Medicina, porém, um pequeno veneno para todos os 
médicos. A partir de então, começou a surgir à distorção da figura do médico que, passou a ser alguém totalmente responsável por qualquer acontecimento que venha a ocorrer com as pessoas tratadas por ele. "Os dois sujeitos humanos diretamente envolvidos, sofrem assim de uma substancial distorção. O cidadão delega parte de si a um poder externo, o médico é levado a assumir uma delegação sempre mais ampla sobre a vida alheia." (BERLINGUER, 1996, P.50). Essa atitude de assumir responsabilidades extras sobrecarrega cada médico individualmente, repercutindo em problemas não só no campo profissional mas, sobretudo, no pessoal, fazendo com que a Medicina seja, como afirma Rodriges (1998) uma das atividades profissionais mais estressantes na atualidade.

Os indivíduos que cederam seus poderes ao médico exigem dele uma postura que vai beirar a relação parental, como já descreveu Freud, nos seus estudos sobre a transferência. Tal situação não seria insustentável se os indivíduos que procurassem um médico tivessem realmente demandas passíveis de solução pela Medicina, e se os médicos que os atendem não quisessem tratar todos os problemas com intervenções exclusivas da Medicina, trazendo também as responsabilidades de outros profissionais para si. Por agirem dessa forma, sobrecarregam também os sistemas de saúde, gerando assim um círculo vicioso de falsa demanda, exigência distorcida e tratamento ineficaz.

Como os médicos ficam sobrecarregados de trabalho, e não estão efetivamente preparados para tratarem problemas que não sejam de ordem biológica, ficam altamente fragilizados perante um sistema que exige deles sabedoria, paciência e boa vontade absolutas. Em sua formação, não foram preparados para saber como agir em tais situações, assim, freqüentemente protegem-se com um dos mecanismos mais básicos de defesa, o enfrentamento² (que pode ser entendido também como uma decorrência da onipotência, já descrita), colocando-se como alguém superior que não deve ser questionado, para evitar que suas fragilidades sejam expostas, o que na verdade só faz alimentar o sistema já distorcido.

A ideologia básica do modelo tradicional baseia-se na crença de que só se o profissional colocar-se como uma pessoa forte e onipotente poderá merecer a confiança e o respeito do cliente. O raciocínio

2 Aqui, não estão sendo considerados os mecanismos de defesa nos moldes descritos pela psicanálise, em especial por Ana Freud. Considera-se, isto sim, a concepção biológica do mecanismo básico de defesa luta/fuga, sendo o primeiro, o mais utilizado, visto ter o médico bastante força (enquanto profissional), dada pela sociedade para "preferir" resignar-se ou fugir frente uma situação ameaçadora.

3 Recomenda-se a leitura de Christophe Dejours sobre o sofrimento no trabalho e ideologias defensivas. subjacente faz supor que é melhor colocar-se numa posição de semideus, criando em torno de seus procedimentos uma aura de mistério e dogmatismo absoluto, sem jamais abrir o jogo e adotando uma conduta rígida e autoritária, do tipo "é assim que eu faço, não admito questionamentos, se quiser ficar comigo tem que se submeter" que de muito ultrapassa as reais necessidades de respeitar seu próprio modo de trabalhar. (MALDONADO, 1978, p. 326).

A cristalização dessa forma de agir cria a alienação já descrita anteriormente, pois todas estas atitudes são vistas como normais. "Também passa a ser normal o fato de ser atendido um número imenso de pacientes num período de tempo absurdamente curto. E tudo passa a ser normal. E os profissionais que atuam na área da saúde assistem desolados e conformados a esse estado de coisas." (ANGERAMI-CAMON 1984, p.13). Essa alienação atua, sobretudo, como uma defesa do próprio médico contra o sofrimento que sua atividade profissional the causa; ${ }^{3}$ ele busca, desse modo, evitar um contato real com aquilo que Ihe é frustrante, o "não saber", o "não poder". Infelizmente, o médico não percebe que quanto mais tenta negar seu sofrimento, refugiando-se na sua fantasia de "ser intocável", mais prejudica a si próprio, pois negar o sofrimento não significa eliminá-lo, pois o mesmo irá "eclodir" de outra forma, como: dificuldades em relacionamentos, alcoolismo, depressão, drogadição, redução do tempo médio de vida, etc. Enfim, a própria qualidade de vida do médico fica ameaçada, o que na atualidade tem sido um ponto de grande preocupação dentro da classe médica.

\section{A ANGÚSTIA DA INCERTEZA}

A angústia consiste em um fenômeno psicológico já há muito conhecido pela Psicologia, Medicina, Filosofia e Literatura, entretanto, foi somente após o surgimento da psicanálise que a mesma ganhou um lugar marcado dentro de nossa cultura. FREUD (1990 a), no início de seus estudos, defendia que a angústia tinha uma etiologia puramente sexual, sendo o resultado do bloqueio da tensão libidinal que não pôde ser descarregada. Mais tarde, principalmente pela influência de outros teóricos da psicanálise como Rank, Freud mudou sua posição em relação a angústia, criando os termos "angústia frente um perigo real", "angústia automática" e "sinal de angustia" que, ampliaram a caracterização dos sintomas de angústia para além da pura frustração da libido, (ROUDINESCO,1998). Assim, encontra-se, posteriormente, na obra de Freud a formulação de que "A psique é dominada 
pelo afeto de ansiedade (angústia) se sentir que é incapaz de lidar por meio de uma reação apropriada com uma tarefa (um perigo) que se aproxima de fora. (FREUD, 1990 b, p.98).

Desse modo, pode-se constatar que a angústia, além de estar relacionada a acontecimentos subjetivos internos, também se manifesta quando da inadaptação do indivíduo frente a algum acontecimento externo desconhecido e/ou frustrante. KUSNETZOFF (1982, p.154) corrobora tal pensamento quando afirma: "Saber pouco sobre um determinado fato e, em conseqüência, ter explicações sumamente fantasiosas com escassa correspondência à realidade do fenômeno, é fato capaz de desencadear angústia" Ao se transportar esta afirmação para uma realidade médica, observa-se que o médico, quando incapacitado de realizar uma de suas mais básicas funções, como por exemplo o diagnosticar, fica frente ao desconhecido e, como afirma Kusnetzoff, desencadeia o sentimento de angústia.

No caso do médico, o agravante, consiste em que ele, como já foi visto, é revestido de um poder social, de uma educação rígida e assertiva, e de um status que perversamente não lhe permitem ter dúvidas ou falhas. $O$ médico é visto (até mesmo por ele próprio) como aquele que deve saber e, se não sabe, é por que não é um bom médico. Quando se depara com sua própria incapacidade, não sabe como reagir, visto que nunca foi educado a não ter respostas, a ser consciente de que tem limites; nesse momento então, sua fantasia de onipotência cai e ele experimenta sentimentos de culpa (individual) advindos da angústia de agora considerar-se impotente, incapaz, ou um médico ruim.

A atual Medicina tecnicista, ao invés de ajudar o médico, contribui ainda mais para o surgimento dessa situação de desamparo. A Medicina vende a propaganda de que com os atuais recursos das ultra-sonografias, ressonâncias magnéticas, endoscopias, laparoscopias, tomografias computadorizadas, etc, não há doença que não possa ser pelo menos diagnosticada (o que qualquer pessoa que trabalha na área da saúde sabe não ser verdade). Porém, a sociedade acredita que essa tecnologia (como mágica) pode detectar todas as patologias existentes, e se em algum caso isso não consegue ser feito, então a falha só pode ser daquele que interpreta os resultados dos aparelhos, ou seja, do médico. Tal situação chega ao ponto, dos próprios médicos acreditarem nessa falácia se auto responsabilizando por "sua incompetência" em lidar com os casos, onde um diagnóstico preciso, fica impossibilitado.

Tudo isso reflete a distorção existente em nossa atual instituição médica, onde a Medicina tem uma visão cada vez mais especializada de homem, aliada a uma megalomania de acreditar que todas as patologias se enquadram em uma forma organicista/determinista de entender o mundo e, o que não se enquadra, não é uma patologia verdadeira.

\begin{abstract}
Ademais, quando não consegue diagnosticar uma lesão orgânica, nasce no médico uma frustração, justamente porque ele não está preparado para investigar, compreender e tratar os distúrbios emocionais... Talvez seja por que na era das máquinas e dos aparelhos, os médicos almejem ser sempre "objetivos". O interesse pelos problemas dos pacientes fica sendo diretamente proporcional à possibilidade de "fotografar", "dosar" ou "radiografar" as queixas por ele relatadas. Se isso não for possível, o médico fica sem saber o que fazer, rotula o paciente de "neurótico" ou algo semelhante e dá sua tarefa por terminada. (PORTO 1996, p.128).
\end{abstract}

Obviamente, a afirmação de PORTO (1996) refere-se unicamente aos maus profissionais, por certo não se pode acreditar que o fenômeno de "rotular pacientes como neuróticos" e, em seguida dispensá-los, seja algo universal na Medicina. Entretanto, essa colocação, chama a atenção para o fato de que o médico atual é despreparado para lidar com toda a gama de patologias que o homem tão "engenhosamente desenvolve", e se este (o médico) fica preso aos conceitos limitados que aprendeu durante sua formação, tomando-os como universais, totais e infalíveis, por certo encontrará a frustração e com ela o sentimento de angústia, desencadeando todos os problemas mencionados anteriormente.

A Medicina transformou-se, assim, em um tabu de perfeição intocável, e o médico em um "ser alienado" incapaz de atribuir falhas a este tabu e, que considera todo e qualquer equívoco, limitação ou imperfeição como sendo proveniente de si próprio. O médico introjeta todas as incapacidades como sendo de caráter individual, sem perceber que está inserido em um meio perverso (educação, instituição médica e sociedade), que não the proporcionou todos os recursos de que necessita para compreender e solucionar os problemas que lhe são apresentados, e o que é pior, lhe faz crer que é onipotente, visto que, conseguiu passar por todas as exigências (acadêmicas) que lhe conferem o título de médico.

A angústia do médico, então, surge quando este não consegue realizar alguma atividade tida como "básica" da Medicina. Isto faz com que acredite na fantasia de estar falhando em dois âmbitos específicos (desenvolvendo assim angústia): o individual (falha como pessoa), e o social (falha como representante de um Tabu). 
A fantasia da falha como pessoa é derivada dos "fantasmas" que o médico trás de sua infância, de suas relações objetais, que lhe fizeram optar por uma profissão como a Medicina. "Assim, todo o indivíduo antes de ser médico, passou por dificuldades e situações penosas infantis, como, por exemplo, a passividade. A vontade de ser médico estaria em parte ligada ao desejo inconsciente de curar e tratar a si mesmo através da pessoa do outro." (MILLAN, 1999, p.76). Desse modo, quando o médico não consegue realizar algum procedimento, tem o sentimento de falha consigo mesmo (e conseqüentemente com suas figuras parentais), o que o leva ao sofrimento (angústia), podendo chegar ao nível patológico de inverter a situação, acreditando ser uma "pessoa ruim" e de estar sendo punido por sua "maldade inata", com a impossibilidade de realizar a tarefa médica.

A fantasia da falha social ocorre, sobretudo, devido à onipotência introjetada pelo médico, pois nessa fantasia acredita ter o poder de sustentar a Medicina e, conseqüentemente, destruí-la caso cometa algum "erro" como, por exemplo, permitir a morte de um paciente. Visto que a função da Medicina é preservar a vida, o médico que permite a morte de um paciente perde sua função e macula a própria instituição. "Os hospitais são instituições comprometidas com o processo de cura, e os pacientes a beira da morte são uma ameaça a esta função precípua... O morrer é uma ameaça às funções dos profissionais e cria sentimentos de impropriedade, incompatíveis com suas funções definidas." (ANGERAMI-CAMON, 1994, p.104). Assim, com sua "falha individual", em sua fantasia, o médico produz uma ameaça a intuição mãe-medicina, e sofre "temendo a punição de ser rejeitado por essa mãe/tabu". O sofrimento implícito aqui é, a angústia de "ser abandonado" pela própria sociedade, visto ser essa sociedade quem legitima o poder da Medicina, tornando-se assim um rejeitado, um ingrato que não soube aproveitar uma oportunidade dada, um "alguém sem lugar". O médico, desse modo, sofre em seu cotidiano a angústia de ser constantemente cobrado por algo, ou por coisas, que Ihe são impossíveis de realizar como, por exemplo, impedir a morte ou ter sempre um diagnóstico exato, como se a Medicina fosse uma espécie de matemática onde se pode controlar todas as variáveis existentes, de maneira absoluta e certeira.

\section{CONSIDERAÇÕES FINAIS}

A teoria psicanalítica, ao remeter o sentimento de angústia, afirma, ainda, que o mesmo vem sempre acompanhado de um outro fenômeno característico: as fobias. Desse modo, o medo é um elemento constante no cotidiano do médico que vivência a angústia, podendo ser caracterizado por um tipo específico de fobia, o medo de errar.

O profissional de Medicina, então, constantemente se auto-vigia para não cometer e, conseqüentemente, ser vítima do erro, visto que na Medicina, tal palavra ganhou uma conotação de blasfêmia. Os profissionais das mais diversas áreas, engenheiros, advogados, dentistas, políticos, cometem erros e, entretanto, nenhum erro profissional "choca" tanto a sociedade quanto o erro do médico, prova disso, é a existência do termo específico "erro médico".

A mensagem implícita aqui é de que todos os profissionais podem ser perdoados por seus erros, mas o médico não. Isso pode ser entendido como uma conseqüência da distorção da Medicina, que tenta negar o caráter humano dos seus profissionais (onipotência extrema), negando-Ihes o direito de errar. Assim, se errar é humano, e se o médico não errar nunca, isso significa que ele é sobrehumano. A própria sociedade acredita nessa falácia, por isso existe um "choque" quando se escuta a expressão "erro médico", já que se espera que ele não erre nunca.

Novamente, o maior prejudicado nessa situação é o médico enquanto indivíduo, visto que passa o tempo todo carregando uma tensão (angústia) extra, o medo de errar. O médico, assim, "chama" toda a responsabilidade do paciente e do tratamento para si, pois se algo sair errado ele será o principal "culpado", e não a equipe como um todo. Isto tende a formar um circulo vicioso: o médico centraliza tudo em si por medo de que ocorra algum erro e, ao centralizar tudo assume todas as responsabilidades; como tudo está centrado nele, precisa redobrar sua vigilância, aumentando assim a tensão, o que favorece a ocorrência de um erro, que o faz centralizar ainda mais as responsabilidades e assim por diante.

Por incrível que pareça, essa prática é ensinada e estimulada nos jovens médicos justamente por aqueles que deveriam combatê-la, os antigos médicos. Como cita MARTINS (1991), isto parece fazer parte de um ritual de iniciação a uma classe de elite, onde o sofrimento é a prova, e a máxima é: "se eu passei por isso, você também deve passar". O problema é que esse sofrimento se cristaliza e passa ser a regra que conduzirá a vida do médico. Desse modo, referindo-se aos excessos a que são submetidos os residentes em Medicina pelos seus staffs, Cousins, citado por MARTINS (1991, p.356) coloca: 
Que espécie de competência científica é razoável se esperar de um médico que não dorme a 32 horas? É uma boa política deixar pacientes gravemente enfermos serem tratados por médicos que estão física e emocionalmente exausto?...foi interessante e significativo para mim observar que a defesa dessas práticas vinham daqueles que tendo sobrevivido a esta experiência e, pareciam determinados a não permitir que outros dela escapassem.

Assim, os médicos são constantemente submetidos a uma angústia que é criada e mantida por eles próprios, sendo tanto vítimas como algozes de um sistema perverso. A responsabilidade cai sempre sobre o indivíduo (o médico), não sobre a classe (instituição médica), como acontece com outras profissões. É possível entender isso quando se estuda a construção dos discursos e falas cotidianas. Por exemplo, não é comum ouvir a expressão "erro da Medicina", ouve-se, isto sim, "erro médico", entretanto, não é comum ouvir-se a frase "erro de engenheiro", ou "erro de pedagogo", ouve-se isto sim, "erro de engenharia", ou então "falha pedagógica".

Desse modo, é possível concluir que o poder social que a Medicina detém cobra um preço alto de cada médico, individualmente. Esse preço é o sofrimento originado da angústia de ter que assumir responsabilidades para com seus pacientes e a própria sociedade, muito além de suas capacidades humanas.

Essa centralização, em torno da figura do médico, acaba por enfraquecer o sistema de saúde como um todo. As atividades nessa área, na prática ficam fragmentadas, e a realização de diagnósticos, tratamentos preventivos e terapêuticos em nível verdadeiramente interdisciplinar, são transformados em utopias. Assim, a população, usuária dos serviços de saúde, termina por ser a mais visivelmente afetada sofrendo diretamente as conseqüências de um sistema distorcido, onde também os médicos, (e demais profissionais da área da saúde) sentirão as conseqüências, apenas de uma forma diferenciada, porém, com a mesma intensidade.

Uma possível saída para esse empasse seria a total e real divisão das responsabilidades sobre o tratamento de um paciente com uma equipe multiprofissional e, principalmente, com o próprio paciente. Claro que a divisão das responsabilidades implicará também em uma diluição do poder que está centralizado. Resta saber, portanto, o que aqueles que centralizam o poder irão preferir: permanecer com poder absoluto dentro da área da saúde, ou ter uma melhor e mais prolongada qualidade de vida. Cabe lembrar, somente, que o médico também é um ser humano como outro qualquer e, portanto, também precisa ter seus limites respeitados, principalmente pela própria instituição que o abriga.

ABSTRACT: This article intends to show how the social status reached by medicine ends up becoming the factor that makes that the general medical class suffers from anguish and sickness. During the day-to-day of the Health institutions, it's possible to observe how the medicine professionals are covered by a social power that brings them a great social prestige at the same time that imposes extreme responsibility. The society demands more and more that the doctor be able to solve their problems in a quick, effective and accurate way; disregardering the human limitation of this profession. Strangely, this way of thinking and acting is stimulated by their own academic formation which makes the medical student - future doctor - really believes in his/her almost superhuman skills. However, when he/she faces the limitations of the daily reality the already graduated doctor becomes frustrated when s/he perceives the impossibility of attending all the healing demands s/he is requested for. Therefore, s/he ends up developing deep anguish feelings, as a result of that frustration. So on his/her social status disapproves the demonstration of having trouble and insecurity, the doctor prohibits himself/herself of showing the anguish felt, endings up suffering in silence and lonely, building his/her own prision, becoming a human being that suffers without showing suffering. As a result, this article aims to be a warning, not only for the medical class, but also for all those who work at the medical area, in the meaning that we should rethink of our attending as professionals.

KEY WORDS: Medicine; Academic formation; Anguish; Health; Doctor.

\section{REFERÊNCIAS}

1 ANGERAMI-CAMON, V. A. (Org.). Psicologia hospitalar: a atuação do psicólogo no contexto hospitalar. São Paulo: Traço, 1984.

2 ANGERAMI-CAMON, V. A. (et al.). Psicologia hospitalar: teoria e prática. São Paulo: Pioneira, 1994

3 BERLINGUER, G. Ética da saúde. São Paulo: Hucitec, 1996.

4 BOULOS, M. Relação médico paciente: o ponto de vista clínico. In: MARCONDES, E. \& ERNESTO, L. G. Educação médica. São Paulo: Sarvier, 1998. p. 50-57.

5 FOUCAULT, M. Vigiar e punir: nascimento da prisão. Petrópolis: Vozes, 1987. 
6 FREUD. S. Publicações pré-psicanalíticas e esboços inéditos. Rio de Janeiro: Imago, 1990 a. Edição Standard Brasileira das Obras Completas de Sigmund Freud, Volume I.

7 FREUD. S. Inibições sintomas e ansiedades. Rio de Janeiro: Imago, 1990 b. Edição Standard Brasileira das Obras Completas de Sigmund Freud, Volume XX.

8 GOFFMAN, E. Manicômios, prisões e conventos. São Paulo: Perspectiva, 1987.

9 ILLICH, I. A expropriação da saúde: nêmesis da Medicina. 4. ed. Rio de Janeiro: Nova fronteira, 1984.

10 KUSNETZOFF, J. C. Introdução a psicopatologia psicanalítica. Rio de Janeiro: Nova fronteira, 1982.

11 LANE, S. T. M. Consciência/alienação: a ideologia no nível individual. In: LANE, S. T. M. (Org.). Psicologia social: o homem em movimento. São Paulo: Brasiliense, 1986. p. 40-47.

12 MALDONADO, M. T. P. Alusão da onipotência na relação médico-cliente. Rev. Bras. Ginecol. Obstetr., São Paulo, v.6, n.4, 1978. p.324-331.

13 MARTINS, L. A. N. Atividades médicas: fatores de risco para a saúde mental do médico. Rev. Bras. Clín. Terap., v.20, n.9, 1991. p.355-364.

14 MELLO FILHO, J. (et al). Psicossomática hoje. Porto Alegre: Artes médicas, 1992.
15 MILLAN, L. R. (et al). O universo psicológico do futuro médico. São Paulo: Casa do psicólogo, 1999.

16 PERAZZO, S. Descansem em paz os mortos dentro de mim Rio de Janeiro: Francisco Alves, 1990.

17 PESSINI, L. (et al.). Problemas atuais de bioética. São Paulo: Loyola, 1994.

18 PORTO, C. C. Exame clínico. 3. ed. Rio de Janeiro: Guanabara koogan, 1996.

19 RODRIGUES, A. L. O stress no exercício da Medicina. Jorn. Paul. Psicossom., v.4, n.19, 1998. p.74-75.

20 ROUDINESCO, E.; PLON, M. Dicionário de psicanálise. Rio de Janeiro: Zahar, 1998.

21 ZAIDHAFT, S. Morte e formação médica. Rio de Janeiro: Francisco Alves, 1990

22 ZIMERMAN, D. E. A formação psicológica do médico. In: MELLO FILHO, J. (et al.). Psicossomática hoje. Porto Alegre: Artes médicas, 1992. p. 64-69.

Endereço do autor: Rua Barra Velha, n¹41 - Bela Vista 88110-160 - São José - SC E-mail: kuluzan@hotmail.com / anpicolli@bol.com.br 